\title{
Germinação e formação de mudas de arroz irrigado sob estresse salino ${ }^{1}$
}

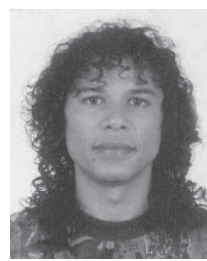

\author{
Luis N. Rodrigues ${ }^{2}$, Pedro D. Fernandes ${ }^{3}$, Hans R. Gheyi ${ }^{3}$ \& Sergio B. A. Viana ${ }^{4}$ \\ ${ }_{1}^{1}$ Parte de Dissertação de Mestrado apresentada pelo primeiro autor ao Programa de Pós-Graduação em Engenharia \\ Agrícola da UFCG \\ ${ }^{2}$ Esc. Agrot. Fed. de Castanhal. CEP 68740-970, Castanhal, PA. Fone: (91) 721-1196. E-mail: gabinete@eafc-pa.gov.br (Foto) \\ ${ }^{3}$ DEAg/CCT/UFCG. Fone: (83) 310-1185. E-mail: pdantas@deag.ufpb.br e hans@deag.ufpb.br \\ ${ }^{4}$ Doutorando em Recursos Naturais, UFCG. E-mail: sbaviana@bol.com.br
}

Protocolo $174-7 / 12 / 2001$

\begin{abstract}
Resumo: Um experimento foi instalado em condições de casa-de-vegetação com o objetivo de se estudar os efeitos da salinidade da água de irrigação sobre a germinação e formação de mudas da cultivar de arroz 'Formoso' (Oryza sativa L.), lançada recentemente pela EMBRAPA para áreas irrigadas. Para os estudos de germinação adotou-se o delineamento inteiramente casualizado, com 5 níveis de salinidade da água de irrigação $\left(\mathrm{N}_{1}=0,5, \mathrm{~N}_{2}=2,5, \mathrm{~N}_{3}=4,5, \mathrm{~N}_{4}=6,5\right.$ e $\mathrm{N}_{5}=8,5 \mathrm{dS} \mathrm{m}^{-1}$ ) e 5 repetições. Para o vigor de plântulas foi adotado um delineamento inteiramente casualizado, em esquema fatorial $(5 \times 2)$ envolvendo 5 níveis de salinidade e 2 épocas de avaliação, com 5 repetições; os níveis de salinidade foram os mesmos e o vigor foi avaliado em duas épocas, aos $8\left(E_{1}\right)$ e aos $13\left(E_{2}\right)$ dias após semeadura (DAS), através de fitomassa seca das raízes, peso das matérias verde e seca da parte aérea, relação raiz/parte aérea, altura de plântula, comprimento radicular e número de folhas. A maior parte das sementes germinou aos 4 DAS. A cultivar 'Formoso' é tolerante à salinidade na fase de germinação, atingindo percentual superior a $87 \%$, em todos os tratamentos. O efeito da salinidade foi intensificado na fase de plântula, reduzindo o seu desenvolvimento inicial.
\end{abstract}

Palavras-chave: salinidade da água, irrigação, vigor, Oryza sativa L.

\section{Germination and formation of rice seedlings under saline stress}

\begin{abstract}
A study was carried out under greenhouse conditions with the objective of verifying the effects of salinity of irrigation water on the germination and seedling vigor of irrigated rice (Oryza sativa L.) cultivar 'Formoso'. Germination and vigor were evaluated adopting a completely randomized experimental design with 5 levels of water salinity - (ECw: 0.5, 2.5, 4.5, 6.5 and $8.5 \mathrm{dS} \mathrm{m}^{-1}$ ) - and 5 replications. Most of the seeds germinated 4 days after sowing (DAS). The 'Formoso' cultivar was found to be tolerant to the tested salinity levels in the germination stage, reaching a germination level of above $87 \%$ (14 DAS) in all the treatments. For the seedling vigor, a completely randomized design was adopted in $5 \times 2$ factorial scheme with 5 replications. The applied salinity levels were the same and the vigor was evaluated through the variables: dry weight of root and shoot, root/shoot ratio, height of seedlings, root length and number of leaves at two different stages ( 8 and 13 DAS). The effect of salinity increased in the seedling phase reducing the vigor.
\end{abstract}

Key words: water salinity, irrigation, vigor, Oryza sativa L.

\section{INTRODUÇÃO}

No Brasil, o cultivo de arroz ocupa o terceiro lugar em área e em volume de produção, entre os cereais, perdendo somente para a soja e o milho. Faz parte da dieta básica da população brasileira e é importante fonte de carboidratos, nutrientes e proteínas (Fageria, 1984). É cultivado em todos os estados brasileiros sob diferentes condições de clima, solo e técnicas de manejo, com produtividade variando de aproximadamente 796 a $5.999 \mathrm{~kg} \mathrm{ha}^{-1}$, de acordo com o nível tecnológico e o sistema de cultivo (Anuário Estatístico do Brasil, 1999).

Com manejo adequado de água e alta tecnologia, é possível se obter, em arroz, os maiores rendimentos por unidade de área e um produto de melhor qualidade, com menores riscos e perdas. No semi-árido do Nordeste brasileiro, devido à irregularidade 
das chuvas, faz-se necessário o emprego de irrigação, com as devidas precauções para se evitar o agravamento dos problemas de salinidade.

Previsões indicam que a população mundial será duplicada nos próximos 50 anos (mais de 10 bilhões em 2050) sendo que grande parte desse aumento demográfico está projetada nos países em desenvolvimento (World Bank, 1990) nos quais se localiza a maior parte dos solos afetados por sais e é maior a demanda de alimentos. Nesse contexto, a incorporação das áreas afetadas por sais, no processo produtivo de alimentos, constitui-se de fundamental importância sob o ponto de vista sócioeconômico (Fageria \& Gheyi, 1997).

Estima-se em aproximadamente $30 \%$ a área afetada por salinidade nos projetos públicos de irrigação no Nordeste brasileiro (Bernardo, 1995). Além de solos com problemas de salinidade, outro fator a ser considerado diz respeito à qualidade das águas utilizadas em irrigação, insatisfatória em boa parte das pequenas propriedades rurais no interior da região (Audry \& Suassuna, 1990; Medeiros, 1992). Para o aproveitamento dessas áreas, são relevantes todos os esforços em se identificar materiais genéticos adaptados para cultivo nessas condições. A rizicultura é uma das opções para exploração dessas áreas, pela possibilidade de lavagem de sais, através do próprio manejo de água utilizada em seu cultivo (FAO/UNESCO, 1973).

Periodicamente, novos materiais genéticos são introduzidos no sistema produtivo, sendo necessários estudos para se avaliar a sua adaptabilidade às condições de solo salinizado. Sabe-se que a tolerância à salinidade varia entre espécies, entre variedades/cultivares de uma mesma espécie e até mesmo entre estádios fenológicos de um mesmo genótipo (Yan et al., 1992; Shannon, 1997).

Considerando-se a necessidade de se conhecer o grau de tolerância da cultivar de arroz 'Formoso' à salinidade, lançada recentemente pela EMBRAPA para áreas irrigadas, foi conduzido este trabalho com o objetivo de se estudar os efeitos de diferentes concentrações de sais na água de irrigação sobre a germinação e formação de mudas.

\section{MATERIAL E MÉTODOS}

Este trabalho foi conduzido em casa de vegetação do Departamento de Engenharia Agrícola do Centro de Ciências e Tecnologia/UFCG, Campus I, Campina Grande, PB, durante os meses de outubro e novembro de 1999. Foram realizados dois experimentos, um para estudos de germinação e o outro para estudos de vigor durante a fase de formação de mudas; em ambos, foram testados cinco níveis de salinidade $(\mathrm{N})$, expressos em termos de condutividade elétrica da água de irrigação $\left(\mathrm{N}_{1}=0,5 ; \mathrm{N}_{2}=2,5 ; \mathrm{N}_{3}=4,5 ; \mathrm{N}_{4}=6,5 \mathrm{e}_{5}=8,5 \mathrm{dS} \mathrm{m}^{-1}\right)$ com cinco repetições, em delineamento inteiramente casualizado.

Nos estudos de germinação, cada repetição foi constituída de 9 recipientes, obtendo-se dados de percentual de germinação em duas contagens, aos 5 dias após a semeadura (DAS) e aos 13 DAS, conforme recomendações contidas em Brasil (1992). No segundo ensaio, para estudo de vigor, foi formado um fatorial ( 5 x 2) envolvendo o fator $\mathrm{N}$ e duas épocas de avaliação (E): $\mathrm{E}_{1}$ aos 8 e $\mathrm{E}_{2}$ aos 13 DAS, sendo a parcela constituída de 4 recipientes.
Em cada recipiente plástico, com capacidade para $350 \mathrm{~mL}$, foram semeadas (profundidade de aproximadamente $1 \mathrm{~cm}$ ) quatro sementes de arroz (Oryza sativa L.), cultivar 'Formoso', recentemente desenvolvida pela EMBRAPA Arroz e Feijão, para cultivo em condições de irrigação e indicada para a região Nordeste. O substrato utilizado no preenchimento dos recipientes foi composto de 3 partes de material de solo +1 parte de húmus. As características físico-hídricas e químicas do solo utilizado no experimento estão apresentadas na Tabela 1.

Tabela 1. Características físico-hídricas e químicas do solo utilizado como substrato

\begin{tabular}{|c|c|c|c|}
\hline Características & Símbolo & Unidade & Valor \\
\hline Areia & - & $\mathrm{g} \mathrm{kg}^{-1}$ & 635,00 \\
\hline Silte & - & $\mathrm{g} \mathrm{kg}^{-1}$ & 198,20 \\
\hline Argila & - & $\mathrm{g} \mathrm{kg}^{-1}$ & 166,80 \\
\hline Classificação textural & - & & Franco-arenoso \\
\hline Densidade global & $\mathrm{dg}$ & $\mathrm{kg} \mathrm{dm}^{-3}$ & 1,37 \\
\hline Densidade das partículas & $\mathrm{dp}$ & $\mathrm{kg} \mathrm{dm}^{-3}$ & 2,68 \\
\hline Porosidade & $\varepsilon$ & $\%$ & 48,88 \\
\hline $\begin{array}{l}\text { Capacidade de } \\
\text { Campo }(33 \mathrm{kPa})\end{array}$ & $\mathrm{CC}$ & $\%$ & 6,80 \\
\hline $\begin{array}{l}\text { Ponto de Murchamento } \\
(1500 \mathrm{kPa})\end{array}$ & PM & $\%$ & 2,73 \\
\hline \multicolumn{4}{|l|}{ Complexo sortivo } \\
\hline Cálcio & $\mathrm{Ca}^{++}$ & $\mathrm{cmol}_{\mathrm{c} \mathrm{kg}} \mathrm{kg}^{-1}$ & 0,38 \\
\hline Magnésio & $\mathrm{Mg}^{++}$ & $\mathrm{cmol}_{\mathrm{c}} \mathrm{kg}^{-1}$ & 0,74 \\
\hline Sódio & $\mathrm{Na}^{+}$ & $\mathrm{cmol}_{\mathrm{c}} \mathrm{kg}^{-1}$ & 0,20 \\
\hline Potássio & $\mathrm{K}^{+}$ & $\mathrm{cmol}_{\mathrm{c}} \mathrm{kg}^{-1}$ & 0,06 \\
\hline Hidrogênio & $\mathrm{H}^{+}$ & $\mathrm{cmol}_{\mathrm{c}} \mathrm{kg}^{-1}$ & 2,12 \\
\hline Alumínio & $\mathrm{Al}^{+++}$ & $\mathrm{cmol}_{\mathrm{c}} \mathrm{kg}^{-1}$ & 0,60 \\
\hline Soma das bases & $\mathrm{S}$ & $\mathrm{cmol}_{\mathrm{c}} \mathrm{kg}^{-1}$ & 1,38 \\
\hline $\begin{array}{l}\text { Capacidade de troca } \\
\text { catiônica }\end{array}$ & СТC & $\mathrm{cmol}_{\mathrm{c}} \mathrm{kg}^{-1}$ & 4,10 \\
\hline Saturação de bases & $\mathrm{V}$ & $\%$ & 33,66 \\
\hline $\begin{array}{l}\text { Percentagem de sódio } \\
\text { trocável }\end{array}$ & PST & $\%$ & 4,88 \\
\hline \multicolumn{4}{|l|}{ Outras determinacões } \\
\hline Carbono orgânico & C-Org. & $\mathrm{g} \mathrm{kg}^{-1}$ & 3,50 \\
\hline Matéria orgânica & M.O. & $\mathrm{g} \mathrm{kg}^{-1}$ & 6,00 \\
\hline Fósforo assimilável & P & $\mathrm{mmg} \mathrm{kg}^{-1}$ & 0,19 \\
\hline pH em água $(1: 2,5)$ & $\mathrm{pH}$ & & 4,80 \\
\hline $\begin{array}{l}\text { CE da suspensão } \\
\text { solo-água }(1: 2,5)\end{array}$ & CEsa & $\mathrm{dS} \mathrm{m}^{-1}$ & 0,14 \\
\hline $\begin{array}{l}\text { CE do extrato } \\
\text { de saturação }\end{array}$ & CEes & $\mathrm{dS} \mathrm{m}^{-1}$ & 0,50 \\
\hline $\begin{array}{l}\text { Relação de adsorção } \\
\text { de sódio }\end{array}$ & RAS & $\left(\mathrm{mmol} \mathrm{L}^{-1}\right)^{1 / 2}$ & 1,84 \\
\hline $\begin{array}{l}\text { Umidade de saturação } \\
\text { da pasta }\end{array}$ & $\theta$ sat & $\mathrm{g} \mathrm{kg}^{-1}$ & 187,70 \\
\hline $\begin{array}{l}\text { Acidez }(\mathrm{pH}) \text { da pasta } \\
\text { saturada }\end{array}$ & $\mathrm{pHs}$ & - & 4,54 \\
\hline
\end{tabular}

As águas de irrigação foram preparadas de modo a se ter uma proporção equivalente de 7:2:1, respectivamente entre $\mathrm{Na}: \mathrm{Ca}: \mathrm{Mg}$, a partir dos sais $\mathrm{NaCl}, \mathrm{CaCl}_{2} \cdot 2 \mathrm{H}_{2} \mathrm{O}$ e $\mathrm{MgCl}_{2} \cdot 6 \mathrm{H}_{2} \mathrm{O}$, relação esta predominante em fontes de água utilizada para irrigação, em pequenas propriedades do Nordeste (Leprun, 1983; Medeiros, 1992). A irrigação foi diária aplicando-se, na primeira semana, $10 \mathrm{~mL}$ da respectiva água por recipiente, conforme o nível de salinidade a ser testado. A partir da segunda semana, foram aplicados $12,14,16,18$ e $20 \mathrm{~mL}$ de água por 
recipiente, respectivamente nos tratamentos $\mathrm{N}_{1}, \mathrm{~N}_{2}, \mathrm{~N}_{3}, \mathrm{~N}_{4} \mathrm{e}$ $\mathrm{N}_{5}$. Este procedimento foi adotado para atender às exigências hídricas e favorecer a lavagem do excesso de sais. A irrigação foi feita duas vezes ao dia, para manter a umidade do substrato próximo à capacidade de campo.

Nos testes de vigor durante a fase de formação de mudas, foram avaliados o crescimento (altura e comprimento radicular) e o desenvolvimento das plântulas (número de folhas, fitomassa, relação raiz/parte aérea) utilizando-se de metodologia descrita por Popinigis (1977) e Marcos Filho et al. (1987).

Os resultados foram interpretados através de análise de variância, com desdobramento dos graus de liberdade em componentes de regressão polinomial; no experimento de vigor houve desdobramento da interação $\mathrm{NxE}$, desprezando-se a comparação de médias do fator época, isoladamente. As análises estatísticas basearam-se em recomendações contidas em Santos et al. (1998) e Ferreira (2000).

\section{RESULTADOS E DISCUSSÃO}

\section{Percentual de germinação (PG)}

As sementes da cultivar Formoso germinaram bem em todos os níveis de condutividade elétrica da água de irrigação (CEa) muito embora tenham sido constatados maiores prejuízos da salinidade sobre a germinação até o $5^{\circ}$ dia após semeadura (DAS) havendo recuperação na segunda avaliação, realizada aos 13 DAS (Fig. 1). No nível $\mathrm{N}_{5}$, a germinação no $5^{\circ} \mathrm{DAS}$ foi reduzida de $14,5 \%$, em relação ao nível $\mathrm{N}_{1}$, sendo alta aos 13 DAS, acima de $87,0 \%$, em todos os níveis salinos, tendo ocorrido, portanto, recuperação dos índices de germinação de uma época de avaliação para a outra. Em geral, a salinidade concorre para retardar a germinação de sementes e a emergência de plântulas.

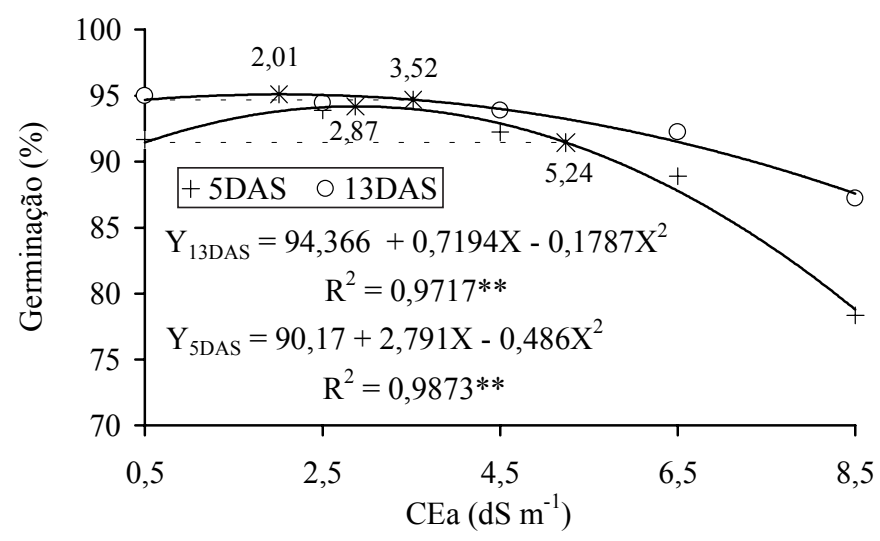

Figura 1. Percentual de germinação do arroz aos 5 e 13 dias após semeadura (DAS), em função da condutividade elétrica da água de irrigação $(\mathrm{CEa})$

Os tratamentos de salinidade da água de irrigação devem ter reduzido o potencial osmótico $\left(\Psi_{\mathrm{o}}\right)$ da solução do solo, notadamente em $\mathrm{N}_{5}$, afetando o processo de embebição pelas sementes de arroz, sendo este efeito mais marcante no $5^{\circ}$ dia, atrasando a germinação. Segundo Basnayake et al. (1994) e O‘Leary (1995), a ocorrência excessiva de sais solúveis no solo acarreta redução do potencial osmótico e, como conseqüência, redução do gradiente de potencial entre o solo e a semente, dificultando o processo de embebição e comprometendo a germinação. Aslam et al. (1993) observaram ser a germinação de sementes de arroz prejudicada por redução na absorção de água, quando postas para germinar em meio salino, e comentam que as diferenças genéticas podem explicar a variação de comportamento de cultivares sob condições de salinidade. Bari et al. (1973), estudando a germinação de sementes de arroz em presença de salinidade, verificaram ser essencialmente osmótico o efeito do sal, uma vez que sementes não germinadas em solução contendo $1,5 \%$ de uma mistura de $\mathrm{Na}_{2} \mathrm{SO}_{4}, \mathrm{NaCl}, \mathrm{CaCl}_{2}$, $\mathrm{MgSO}_{4}$ e $\mathrm{NaHCO}_{3}$, na proporção 8:6:2:2:1 (CEa $\left.\cong 23 \mathrm{dS} \mathrm{m}^{-1}\right)$, foram capazes de germinar quando transferidas para água destilada; caso não germinassem, seria devido à toxidez.

Tomando-se como base o modelo matemático obtido no $5^{\circ}$ dia (Fig. 1) nota-se ter ocorrido incremento do percentual de germinação até o ponto máximo da curva $\left(\mathrm{CEa}=2,87 \mathrm{dS} \mathrm{m}^{-1}\right)$ decrescendo a partir desse nível de salinidade o número de sementes germinadas, de modo que em CEa de 5,24 dS m obteve-se uma germinação equivalente $(91,4 \%)$ à conseguida com água de $0,5 \mathrm{dS} \mathrm{m}^{-1}$ de condutividade elétrica; houve decréscimo da germinação, relativo a $\mathrm{N}_{1}$, somente a partir de $5,24 \mathrm{dS} \mathrm{m}^{-1}$ (ponto crítico). Na segunda avaliação (13 DAS) também houve incremento da germinação nos níveis mais baixos, embora em proporção menor, com ponto de máxima na CEa de 2,01 dS $\mathrm{m}^{-1}$, decrescendo em seguida; pode ser considerado como ponto crítico o valor de CEa igual a 3,52 dS $\mathrm{m}^{-1}$, em que se obteve o mesmo percentual de germinação registrado com $0,5 \mathrm{dS} \mathrm{m}^{-1}(94,7 \%)$.

Bhumbla et al. (1968) constataram que sementes de arroz postas para germinar em solução salina de condutividade elétrica igual a $8 \mathrm{dS} \mathrm{m}^{-1}$, após 10 dias, tiveram decréscimo na germinação, superior a 50\%; no entanto, em contagem feita após vinte dias, só constataram esse nível de redução com CEa de $12 \mathrm{dS} \mathrm{m}^{-1}$, denotando ser o arroz tolerante à salinidade na fase de germinação. Narale et al. (1969), trabalhando com a cultivar Dular de arroz, em meio salino, observaram ser a germinação afetada pelo efeito osmótico e encontraram o valor de CEa igual a $15,8 \mathrm{dS} \mathrm{m}$ m $^{-1}$ como crítico para $50 \%$ de redução na germinação de sementes. No presente estudo, não mais se constatou germinação depois de 13 dias da semeadura, sendo observado no nível mais elevado de salinidade estudado (CEa de $8,5 \mathrm{dS} \mathrm{m}^{-1}$ ) um percentual de germinação equivalente a $87 \%$. Pela equação de regressão obtida estima-se, para 50,0\% de redução na germinação, uma $\mathrm{CEa}$ igual a $18,4 \mathrm{dS} \mathrm{m} \mathrm{m}^{-1}$, podendose dizer que a cultivar Formoso é altamente tolerante à salinidade, nessa fase.

Campos (1986) observou diferenças de sensibilidade ao estresse salino entre cultivares de arroz, a partir de potencial osmótico igual ou inferior a $-0,4 \mathrm{MPa}\left(\mathrm{CEa} \cong 11,1 \mathrm{dS} \mathrm{m}^{-1}\right)$. Alguns autores citam ser o arroz tolerante à salinidade durante a germinação e sensível no estádio de plântula, quando se encontra com 2 a 3 folhas (IRRI, 1967; Fageria, 1984; Gheyi \& Barros, 1987).

\section{Fitomassa}

Foi interativo o efeito dos fatores ' $\mathrm{N}$ ' (níveis de salinidade) e 'E' (épocas de avaliação de vigor) significando que em todas 
as variáveis de fitomassa, o efeito da salinidade variou entre as duas épocas de avaliação. As equações matemáticas com as respectivas representações gráficas, para as variáveis envolvendo fitomassa, estão apresentadas na Figura 2.

Em relação à fitomassa fresca da parte aérea (FFPA) o efeito foi linear (Figura 2A) e, segundo os valores de coeficiente angular, houve decréscimo de $2,90 \mathrm{mg}$ por cada incremento
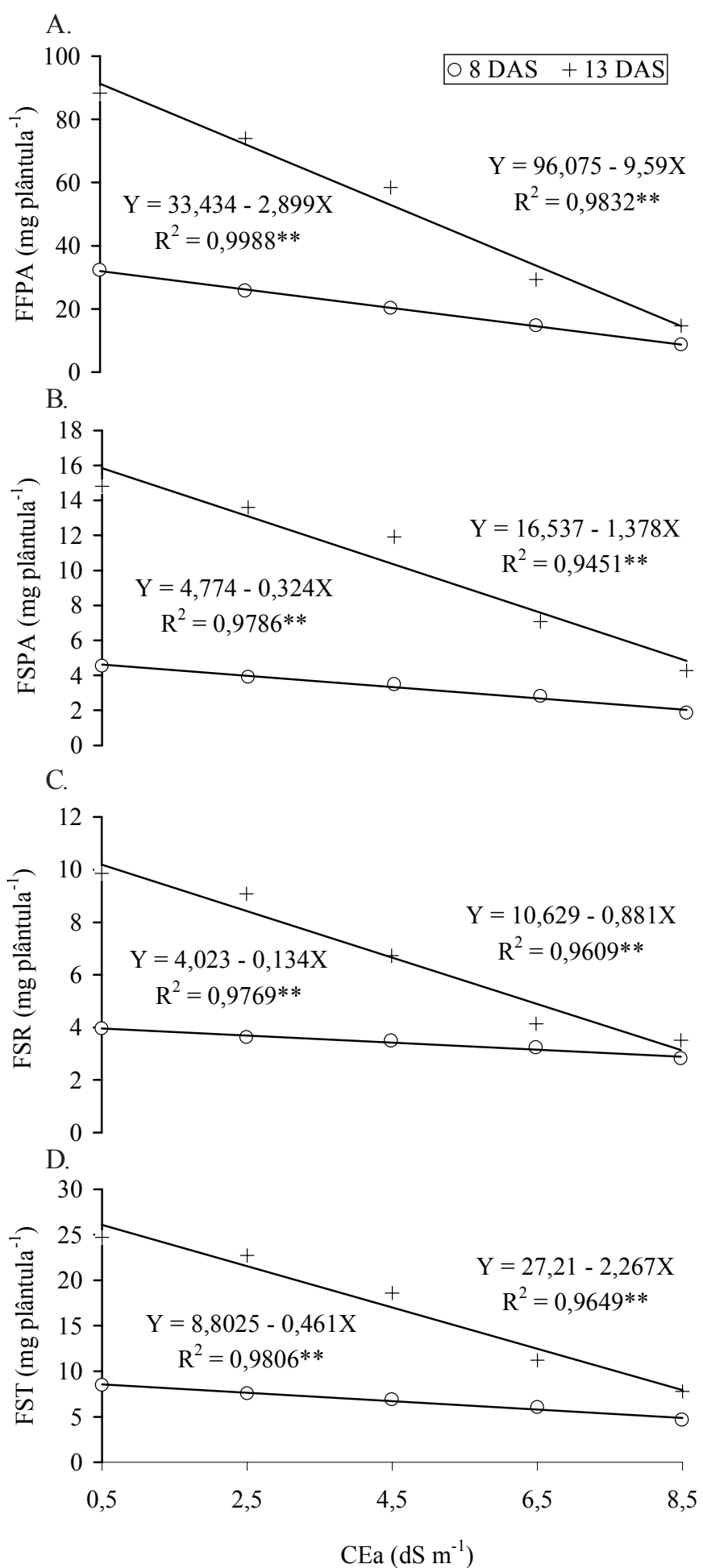

Figura 2. Fitomassa fresca (FFPA) (A) e seca (FSPA) (B) da parte aérea, fitomassa seca de raízes (FSR) (C) e fitomassa seca total (FST) (D) aos 8 e 13 dias após semeadura (DAS) em função da condutividade elétrica da água de irrigação (CEa) unitário da CEa, aos 8 DAS e de $9,59 \mathrm{mg}$ aos 13 DAS, resultando em reduções (relativas a $\mathrm{N}_{1}$ ) de 18,1 e de $21,0 \%$ por aumento unitário da $\mathrm{CEa}$, respectivamente aos 8 e 13 DAS. As plântulas foram, portanto, mais sensíveis à salinidade na segunda época, aos 13 DAS $\left(\mathrm{E}_{2}\right)$, diminuindo a produção de matéria fresca à medida que aumentavam os níveis de salinidade.

Diminuiu, portanto, a tolerância à salinidade da cultivar de arroz 'Formoso', após a germinação, resultando em maior sensibilidade na fase de plântula, estando esses dados em concordância com os encontrados na literatura (Pearson \& Ayers, 1960; Gheyi \& Barros, 1987; Yan et al, 1992); este comportamento tem implicações diretas para o plantio de arroz em solos afetados por sais, sendo necessária uma quantidade maior de sementes (20 a 30\%) para compensar a morte de plântulas.

Assim como para FFPA, a salinidade (N) afetou $(\mathrm{p}<0,01)$ a produção de fitomassa seca das raízes (FSR) e da parte aérea (FSPA), sendo também significativo o efeito interativo entre os fatores.

Aos 8 DAS, com base nas equações apresentadas nas Figuras $2 \mathrm{~B}$ e 2C, a FSPA diminuiu $0,32 \mathrm{mg}$ por incremento unitário da condutividade elétrica da água de irrigação, aumentando para 1,38 mg aos $13 \mathrm{DAS}$, enquanto os valores correspondentes de decréscimo para FSR foram 0,13 e $0,88 \mathrm{mg}$, respectivamente. Aos 8 DAS esses valores correspondem a taxas de decréscimo, relativas a $\mathrm{N}_{1}$, da ordem de 7 e $3,39 \%$, por incremento unitário da CEa, sendo mais afetada, portanto, a parte aérea; aos 13 DAS o efeito da salinidade sobre o acúmulo de fitomassa na planta se intensificou, porém, de forma mais acentuada sobre as raízes, resultando em taxas de decréscimo para FSPA e FSR equivalentes e da ordem de 8,7 e $8,65 \%$, respectivamente. Campos (1986) observou, entre sete cultivares de arroz, reduções significativas de fitomassa, sendo a parte aérea menos afetada que o sistema radicular, em níveis altos de salinidade; aos 10 DAS, o autor verificou reduções na fitomassa da parte aérea de 14,6 e 25,1\%, em relação ao controle (água destilada) quando eram utilizadas águas de $-0,4 \mathrm{MPa}$ e $-0,8 \mathrm{MPa}$ de $\mathrm{NaCl}$ (CEa de aproximadamente 11,1 e 22,2 $\mathrm{dS} \mathrm{m}^{-1}$, respectivamente); as reduções, nesse mesmo período, na fitomassa de raiz, foram de 14,3 e 30,0\%. Comparando-se esses resultados com os do presente trabalho, nota-se ser a cultivar 'Formoso' menos tolerante que as utilizadas por aquele autor (IAC 25, IAC 47, IAC 165, CNA 796019, Lebonnet, IRAT 112 e CICA 8). Fageria et al. (1981), estudando o desenvolvimento de cultivares de arroz em condições de salinidade, verificaram diferença varietal no peso da matéria seca, atribuída a fatores como decréscimo do potencial osmótico da solução do solo, acúmulo de íons específicos em nível tóxico e alterações nutricionais da planta.

A cultivar de arroz 'Formoso' foi muito sensível no nível $\mathrm{N}_{5}$ $\left(\mathrm{CEa}=8,5 \mathrm{dS} \mathrm{m}^{-1}\right)$ com reduções de fitomassa superiores a $60 \%$. Com base nos decréscimos, percebe-se que as duas variáveis - FSPA e FSR - foram mais afetadas aos 13 DAS $\left(\mathrm{E}_{2}\right)$, diminuindo a tolerância à salinidade com o crescimento da plântula, conforme constatado também em FFPA. Outra observação diz respeito à variação da FSR em relação à FSPA, entre as duas épocas de avaliação, notando-se certa relação entre diminuição da tolerância do arroz e agravamento dos efeitos da salinidade sobre o desenvolvimento das raízes. 
Analisando-se a produção de FSPA nas duas épocas de avaliação, dentro de cada nível salino (E em N), verifica-se terem as plântulas aumentado a acumulação de matéria seca da parte aérea, entre o $8^{\circ}\left(E_{1}\right)$ e o $13^{\circ}\left(E_{2}\right)$ DAS, em todos os níveis salinos. Entretanto, para a FSR houve acréscimo de fitomassa apenas nos três níveis iniciais de CEa, entre as duas épocas de avaliação; em níveis mais altos $\left(6,5\right.$ e $\left.8,5 \mathrm{dS} \mathrm{m}^{-1}\right)$ não houve diferenças significativas na matéria seca acumulada nas raízes entre o $8^{\circ}$ e $13^{\circ}$ DAS (Fig. 2C), devido ao efeito mais severo da salinidade sobre o sistema radicular aos 13 DAS. Em $\mathrm{N}_{5}$, a FSPA evoluiu $32,6 \%$, entre as duas datas, enquanto a FSR evoluiu menos, cerca de $24,8 \%$.

Com relação a fitomassa seca total (FST), foram significativos ( $p<0,01)$ ambos os fatores estudados e a interação entre eles ( $\mathrm{N}$ x E). Pelos modelos matemáticos e representação gráfica contida na Figura 2D, observa-se semelhança do efeito da salinidade sobre a fitomassa total, em relação às variáveis discutidas anteriormente.

$\mathrm{O}$ aumento da salinidade afetou linearmente a FST, com reduções absolutas de 0,46 e 2,27 mg por aumento unitário de $\mathrm{CEa}$ aos 8 e 13 DAS, respectivamente, correspondendo a decréscimos relativos a $\mathrm{N}_{1}$, de 5,38 e $8,69 \%$, respectivamente. O decréscimo relativo médio (entre 8 e 13 DAS) estimado para o tratamento de $6,5 \mathrm{dS} \mathrm{m}^{-1}$ foi de $56,3 \%$, bastante aproximado ao valor registrado por Pearson et al. (1966) quando verificaram redução de $50 \%$ em relação à testemunha, no peso da matéria seca de plântulas de arroz (média de 14 cultivares) para condutividade elétrica da água de $6,4 \mathrm{dS} \mathrm{m}^{-1}$.

Em apenas cinco dias aumentou o efeito prejudicial da salinidade da água de irrigação sobre todas as variáveis de fitomassa, ficando bem caracterizado o aumento de sensibilidade ao estresse salino na fase de plântula.

\section{Relação raiz parte aérea $(\mathrm{R} / \mathrm{PA})$}

Através dessa relação, analisa-se que parte da planta é mais afetada pela salinidade. $\mathrm{O}$ efeito dos níveis salinos foi linear em relação à primeira época de avaliação $\left(E_{1}=8 \mathrm{DAS}\right) \mathrm{e}$ quadrático na segunda época $\left(E_{2}=13\right.$ DAS). As curvas de ajustes estão representadas na Figura $3 \mathrm{~A}$. Em $\mathrm{E}_{1}$ ocorreu acréscimo na $\mathrm{R} / \mathrm{PA}$, da ordem de $6,94 \%$ por aumento unitário de CEa além de $\mathrm{N}_{1}$, significando efeito mais acentuado sobre a parte aérea nessa época. Aos 13 dias após semeadura, houve mudanças nessa relação, passando a ser quadrático o efeito da salinidade, ocasião em que a R/PA se reduziu com o incremento da CEa até $3,99 \mathrm{dS} \mathrm{m}^{-1}$, com tendência de aumento acima desse nível, ocorrendo acréscimo relativo de R/PA (com base em $\mathrm{N}_{1}$ ) apenas quando a CEa excedeu a 7,48 $\mathrm{dS} \mathrm{m}^{-1}$.

Apesar da parte aérea ter sido mais sensível à salinidade que o sistema radicular aos $8 \mathrm{DAS}$ (taxas de decréscimo relativo por aumento unitário de CEa de 7 e 3,39\%, respectivamente para FSPA e FSR), nela houve maior acúmulo de fitomassa entre o $8^{\circ}$ e o $13^{\circ}$ dia após semeadura (Figs. 2B, C e 3A) em todos os níveis de salinidade. Com base nas respectivas equações de regressão, nota-se que a fitomassa seca da parte aérea aumentou aproximadamente 344, 330, 312, 284 e 239\% em $\mathrm{N}_{1} \ldots \mathrm{N}_{5}$, de 8 para 13 DAS, enquanto estes valores foram de apenas $258,228,195,156$ e $109 \%$ para FSR. O fato, muito provavelmente é característico da espécie em estudo, uma vez que a tendência de maior acúmulo de FSPA independeu da salinidade.
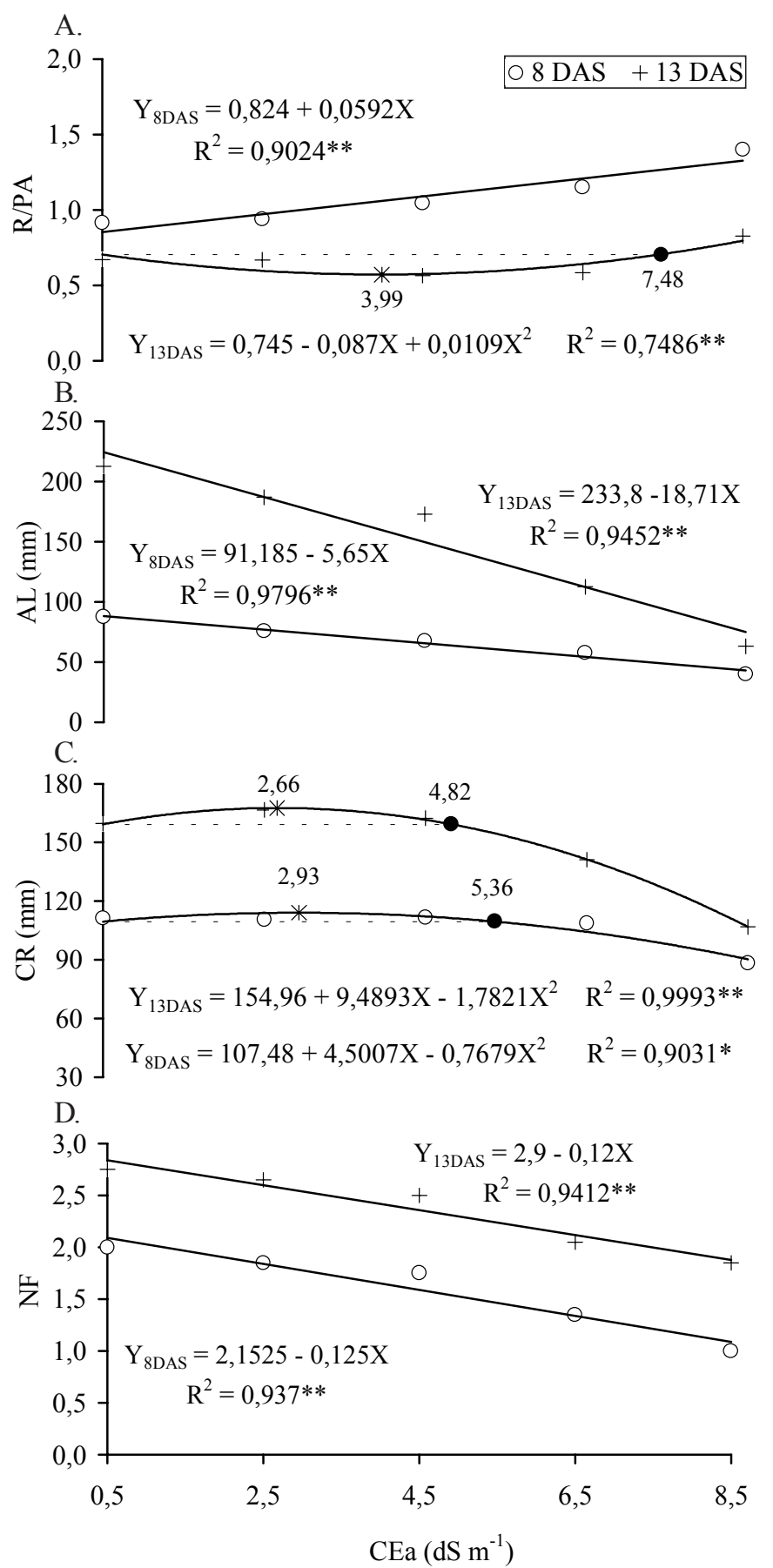

Figura 3. Relação raiz parte aérea $(\mathrm{R} / \mathrm{PA})(\mathrm{A})$, altura de plântulas $(\mathrm{AL})(\mathrm{B})$, comprimento radicular $(\mathrm{CR})(\mathrm{C})$ e número de folhas (NF) (D) aos 8 e 13 dias após semeadura (DAS) em função da condutividade elétrica da água de irrigação (CEa)

Fageria et al. (1981) e Fageria (1984) verificaram ser a parte aérea de plantas de arroz mais sensível em níveis altos de salinidade que as raízes. No presente trabalho, as plântulas em níveis maiores de salinidade, notadamente $\mathrm{N}_{5}$, tinham uma coloração verde-escura nas folhas e início de necrose no ápice foliar devido, provavelmente, à acumulação de sódio. Segundo alguns autores (Bernstein, 1975; Shannon et al., 1997), as raízes são diretamente expostas aos ambientes salinos, mas seu crescimento é menos afetado que a parte aérea, aumentando, conseqüentemente, a relação R/PA. Resultados diferentes foram 
obtidos por Bari et al. (1973), observando maior sensibilidade do sistema radicular de plantas de arroz submetidas à salinidade; Campos (1986) também verificou, em algumas cultivares de arroz, ser a parte aérea das plântulas menos afetada (10 DAS), pois a R/PA diminuiu quando o potencial osmótico se tornou mais negativo.

\section{Altura de plântulas}

As condições de estresse salino, impostas à cultivar, afetaram significativamente a altura da parte aérea (Fig. 3B), com efeito linear nas duas épocas de avaliação $(p<0,01)$ havendo também interação significativa. A altura sofreu progressivas reduções a partir de $\mathrm{N}_{1}\left(0,5 \mathrm{dS} \mathrm{m}^{-1}\right)$ e o efeito da salinidade aumentou na segunda época de avaliação. Com base no coeficiente angular das equações, a cada incremento unitário da CEa a altura diminuiu 5,65 $\mathrm{mm}$ aos $8 \mathrm{DAS}$, sendo muito maior o efeito aos $13 \mathrm{DAS}$, pois a diminuição atingiu 18,7 $\mathrm{mm}$; em termos relativos a $\mathrm{N}_{1}$, a altura de plantas decresceu $6,39 \%$ por incremento unitário de CEa aos 8 DAS e $8,34 \%$ aos 13 DAS. Datta (1972) observou, também, reduções marcantes na altura de cultivares de arroz sob estresse salino. De acordo com Campos (1986), as plântulas adversamente afetadas pela salinidade crescem mais lentamente e são atrofiadas; esse autor verificou decréscimos significativos no comprimento da parte aérea das plântulas de 7 cultivares, aos 10 DAS, sendo as reduções mais drásticas entre plântulas dos tratamentos $-0,4 \mathrm{MPa}$ e $-0,8 \mathrm{MPa}(55,1 \%)$ que entre as do controle (água destilada) e as de $-0,4 \mathrm{MPa}(21,2 \%)$.

As plântulas aumentaram a altura entre o $8^{\circ}$ e o $13^{\circ}$ dia, em todos os níveis salinos sendo, entretanto, bem maior o incremento nos níveis mais baixos de salinidade; irrigando-se com água de $0,5 \mathrm{dS} \mathrm{m}^{-1}$, a altura aumentou $143,5 \%$, entre as duas datas, enquanto não passou de $58 \%$ no nível mais alto de concentração salina $\left(8,5 \mathrm{dS} \mathrm{m}^{-1}\right)$. A salinidade diminuiu progressivamente o vigor, originando plântulas cada vez menores e, conseqüentemente, com menor fitomassa, como observado em itens anteriores.

\section{Comprimento radicular}

Os níveis salinos afetaram significativamente o comprimento radicular. Ao contrário das variáveis envolvendo fitomassa e de altura da parte aérea, o comprimento radicular só foi afetado pelos tratamentos mais elevados de salinidade notando-se, inclusive, tendência de maior crescimento das raízes nos níveis mais baixos de $\mathrm{CEa}$; aos $8 \mathrm{DAS}$, o crescimento foi favorecido com uso de água com até $2,93 \mathrm{dS} \mathrm{m}^{-1}$ de condutividade elétrica, enquanto aos 13 DAS esse valor baixou para 2,66 dS m-1 (Fig. 3C). A partir desses níveis de condutividade, o comprimento das raízes foi decrescente, sendo considerados pontos críticos os valores de CEa de 5,36 aos 8 DAS e de 4,82 $\mathrm{dS} \mathrm{m}^{-1}$, aos 13 DAS, a partir dos quais o crescimento das raízes foi menor que em $0,5 \mathrm{dS} \mathrm{m}^{-1}$. Tanto o ponto de máximo como o ponto crítico foram maiores aos $8 \mathrm{DAS}$; portanto, mais uma vez constata-se ter sido a cultivar 'Formoso' mais sensível à salinidade na segunda época de avaliação, a exemplo das variáveis já analisadas, reforçando que a sensibilidade ao estresse salino se intensifica na fase de plântula. As médias obtidas em $\mathrm{E}_{2}(13$ DAS) diferiram significativamente das obtidas em $\mathrm{E}_{1}$, nos 5 níveis salinos estudados. Campos (1986) também verificou, aos 10 DAS, decréscimos significativos no comprimento total das raízes de plântulas, em sete cultivares de arroz, sendo maiores os decréscimos entre os níveis mais altos de salinidade, chegando a 55,1\% entre os tratamentos -0,4 MPa e -0,8 MPa e sendo de apenas $4,8 \%$ entre o controle e - $0,4 \mathrm{MPa}$.

Comparando-se os dados de comprimento radicular (CR) com os de FSR, verifica-se ter sido menos afetado o comprimento (alongamento) que o peso de matéria seca das raízes, no estádio de plântula.

\section{Número de folhas}

O número de folhas foi afetado linearmente pelos níveis de salinidade, aos 8 e 13 DAS (Fig. 3D), percebendo-se certo grau de paralelismo entre os traçados, pelo fato de não ter sido

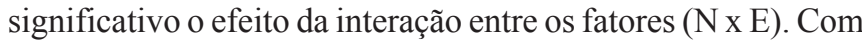
base nas equações de regressão obtidas para NF, aos 8 e 13 DAS (Fig. 3D), constata-se, na primeira época, decréscimo linear do número de folhas em 5,98\% por incremento unitário de $\mathrm{CEa}$, comparado a $\mathrm{N}_{1}$, enquanto em $\mathrm{E}_{2}$ este valor foi reduzido a $4,23 \%$. Nesse contexto, a emissão de folhas, ao contrário das variáveis de fitomassa e altura, foi menos afetada pela salinidade na fase de formação de mudas, sobretudo com o passar do tempo, denotando não ser um bom parâmetro de avaliação dos efeitos da salinidade em arroz; isso ocorre porque parte dos efeitos da salinidade sobre esta variável é apenas de retardar a emissão foliar, como pode ser constatado pela redução da taxa de decréscimo relativo de NF, observada entre 8 e 13 DAS, anteriormente abordada.

\section{CONCLUSÕES}

1. A cultivar 'Formoso' de arroz é tolerante à salinidade na fase de germinação, embora o uso de água salina prolongue o período para as sementes germinarem.

2. Na germinação, as sementes podem ser irrigadas com água de até $3,52 \mathrm{dS} \mathrm{m}^{-1}$ de condutividade elétrica.

3. O efeito da salinidade é intensificado na fase de plântula, entre 8 e 13 dias após semeadura, causando decréscimo linear de fitomassa, altura de parte aérea e número de folhas.

4. Na fase de plântula, o estresse salino prejudica mais a parte aérea que o sistema radicular.

5. O número de folhas não deve ser utilizado como parâmetro na avaliação dos efeitos de salinidade em arroz.

\section{LITERATURA CITADA}

Anuário Estatístico do Brasil, 59. 1-1655, 1999. Rio de Janeiro: IBGE, 1999.

Aslam, M.; Qureshi, R.H.; Ahmed, N. A rapid screening technique for salt tolerance in rice (Oryza sativa L.). Plant and Soil, Dordecht, v.150, p.99-107, 1993.

Audry, P.; Suassuna, J. A qualidade da água na irrigação do trópico semi-árido - um estudo de caso. In: Seminário Franco Brasileiro de Pequena Irrigação, 1990. Recife, Anais. Recife (s.n.), 1990. p-147-153.

Bari, G.; Hamid, A.; Awan, M.A. Effect of salinity on germination and seedling growth of rice varieties. International Rice Comission News Letter. Los Baños, v.22, n.3, p.32-36, 1973. 
Basnayake, J.; Cooper, M.; Ludlow, M.M.; Henkell, R.G. Combining ability variation for osmotic adjustment among a selected range of grain sorghum (Sorghum bicolor (L) Moench). Field Crops Research, Amsterdam, v. 38, p.147-155, 1994

Bernardo, S. Manual de irrigação e drenagem. 6.ed. Viçosa: UFV, Imprensa Universitária, 1995. 657p.

Bernstein, L. Effects of salinity and sodicity on plant growth. Annual Review of Plant Phytopathology, Stanford, v.13, p.295-312, 1975.

Bhumbla, D.R.; Singh, B.; Singh, N.T. Effects of salt on seed germination. Indian Journal of Agronomy, New Delhi, v.13, p.181-5, 1968.

Brasil. Ministério da Agricultura e Reforma Agrária. Regras para análise de sementes. Brasília: DNDV/CLAV, 1992.365p.

Campos, I.S. Efeitos de diferentes potenciais osmóticos na germinação e crescimento do arroz. Fortaleza: Universidade Federal do Ceará, 1986. 112p. Dissertação Mestrado

Datta, S.K. A study of salt tolerance of twelve varieties of rice. Current Science, Bangalore, v.41, n.12, p.456-457, 1972.

Fageria, N.K. Adubação e nutrição mineral da cultura de arroz. Rio de Janeiro: Ed. Campus: EMBRAPA. 1984. 341p.

Fageria, N.K.; Barbosa Filho, M.P.; Gheyi, H.R. Avaliação de cultivares de arroz para tolerância à salinidade. Pesquisa Agropecuária Brasileira, Brasília, v.16, n.5, p.677-681, 1981.

Fageria, N.K.; Gheyi, H.R. Melhoramento genético das culturas e seleção de cultivares. In: Gheyi, H.R.; Queiroz; J.E.; Medeiros, J.M (ed.). Manejo e controle da salinidade na agricultura irrigada. Campina Grande: UFPB-SBEA., 1997. p.363-383.

FAO/UNESCO. Irrigation, drainage and salinity. An international sourcebook. Paris: Hutchison. 1973. 510p.

Ferreira, P.V. Estatística experimental aplicada à agronomia. Maceió: UFAL/EDUFAL/FUNDEPES, 2000. 422p.

Gheyi, H.R.; Barros, A.D. Seleção de cultivares de arroz irrigado para solos salino-sódicos. I. Ensaios de germinação e crescimento. Pesquisa Agropecuária Brasileira, Brasília, v.22, n.7, p.719-723, 1987.

IRRI - International Rice Research Institute. Annual Report, Los Baños, Philipines. 1967.302p.
Leprun, J.C. Primeira avaliação das águas superficiais do Nordeste. In: Relatório de fim de convênio de manejo e conservação do solo do Nordeste brasileiro. Recife: SUDENE, 1983.p.91-149.

Marcos Filho, J.; Cícero, S.M.; Silva, W.R. Avaliação da qualidade de sementes. Piracicaba: FEALQ, 1987. 230p.

Medeiros, J.F. Qualidade da água de irrigação e evolução da salinidade nas propriedades assistidas pelo 'GAT' nos estados do RN, PB e CE. Campina Grande: UFPB/CCT, 1992. 137 p. Dissertação Mestrado

Narale, R.P.; Subramanvan, T.K.; Mukheriee, H.T.. Influence of salinity on germination, vegetative growth and grain yield of rice (Oryza sativa L.). Agronomy Journal, Madison, v.61, n.3, p.341-344, 1969.

O’Leary, J.W. Adaptive components of salt tolerance. In: Pessarakli, M. (ed.) Handbook of plant and crop physiology. New York: Marcel Dekker, Inc., 1995. p.577-585.

Pearson, G.A.; Ayers A.D. Rice as a crop for salt affected soil in process of reclamation. U.S.D.A. Research Service Production Research Report, v.43, p.1-13, 1960.

Pearson, G.A.; Ayers A.D.; Eberhard, D.L. Relative salt tolerance of rice during germination and early seedling development. Soil Science, Baltimore, v.102, n.3, p.151-156, 1966.

Popinigis, F. Fisiologia da semente. Brasília: AGIPLAN, 1977. 289 p.

Santos, J.W.; Moreira, J. de A.N.; Beltrão, N.E. de M. Avaliação do emprego dos testes de comparação de médias na revista Pesquisa Agropecuária Brasileira (PAB) de 1980 a 1994. Pesquisa Agropecuária Brasileira, Brasília, v.33, n.3, p.225-230, 1998.

Shannon, M.C. Genetics of salt tolerance in higher plants. In: Jaiwal, P.K.; Singh, R.P.; Gulati, A. (ed.). Strategies for improving salt tolerance in higher plants. Oxford: BIJ, 1997, p.265-289.

World Bank/UNDP. Irrigation and drainage research. Washington, DC: World Bank/UNDP. 1990, 19p.

Yan, X.; Zheng, S.; Kuang, Y. Rice genotypes differing in salt tolerance. II. Short-term kinetics of $\mathrm{NaCl}$ absorption and translocation in intact plants. Journal of Plant Nutrition, New York, v.15, p.2667-2668, 1992. 